\title{
The Reactive Power Support Strategy based on Dual-loop Control for Three-phase Grid-connected Inverter
}

\author{
WAN Qian ${ }^{1,2 *}$, Xia Chengjun ${ }^{1}$, Azeddine Houari $^{2}$, Zhao Xue $^{1}$, Xia Chengjun ${ }^{1}$, Zheng Xiaotian $^{1}$ and Huang Chuyin ${ }^{1}$ \\ ${ }^{1}$ South China University of Technology, College of Electric Power, Wushan Road, Guangzhou 510640, China \\ ${ }^{2}$ IREENA Laboratory, University of Nantes, 37 boulevard de l'université, Saint-Nazaire 44602, France
}

\begin{abstract}
Renewable energy sources (RESs) generally connected with electric power system via power electronic interface. This paper presents a reactive power and voltage $(\mathrm{Q} / \mathrm{V})$ control strategy of three-phase photovoltaic (PV) system to offering reactive power based on the typical dual-loop control topology. It is worth mentioning that control strategy can support reactive power when a low voltage fault occurs in AC bus without additional compensation device. With the help of the decoupling control, the PV array can generate active power as much as possible in variable external solar radiation conditions. The voltage of PV arrays is adopted as the objective, which on account of the easy availability and controllability of voltage, to control output active power. Besides, accurately modeling process from a PV cell to PV array is described in the beginning to acquire the P-V and V-I characteristics of PV arrays, which promote the designment of $\mathrm{Q} / \mathrm{V}$ control.
\end{abstract}

\section{Introduction}

Due to the conflict of the fast development of world economy and fossil energy lacking, and climate changes caused by power generation by burning of fossil fuels, it is inevitable to develop RESs on a large scale. Converting renewable energy like solar energy, wind power, geothermal energy, and bioenergy into electrical energy is the most efficient and proven technique so far. Electrical energy is an independent and interesting transient vector that provides a great way to incorporate RESs through power generations, power converters, transmissions, and energy storages.

Photovoltaic (PV) system is one of the most mature RESs power generation technologies in the world, which is also the geographically most distributed measures of electricity production worldwide. It makes full use of solar radiation energy with the advantages of modularization, scalability in the generation and simple installation. Besides, the solar radiation as clean, renewable energy, it produces no pollution and never run out, hence achieved the policy support. A photovoltaic cell firstly developed in Bell Laboratories, America. Until now, Japan and Germany have mastered the most advanced PV system technology in the world. And China has occupied the largest installed and total solar power capacity globally [1].

In the condition that PV arrays as the main electrical sources for supply power, it is worth mentioning that the inverter control strategy can support reactive power when a low voltage fault occurs in AC bus without additional compensation device. Therefore, this paper introduced the PV system in four parts. 1) the detailed and accurate modeling of PV arrays; 2) acquiring output characteristics of PV array, P-V and V-I parameters are included; 3) The typical dual loop control and the improved reactive power and voltage $(\mathrm{Q} / \mathrm{V})$ control for three-phase grid-connected inverter; 4) conclusions and discussions of simulation results.

\section{Modeling of PV Array}

A PV cell, or solar cell, is the most basic electrical unit that converters solar radiation into electrical energy. In normal conditions, multiple cells that connected in series or/and parallel constitute a module or panel, which played the role of protecting semiconductor wafer in cells with tempered glasses, encapsulant and so on [2]. In order to generate cumulative voltage or/and current, a PV array implemented by strings of panels that connected in parallel at the same time, with each string consists of modules connected in series.

\subsection{Solar Cell Model}

The equivalent circuit of a general PV cell is shown in Fig. 1. The practical PV module includes $R_{p}$, the parasitic parallel (shunt) resistance and $R s$, the series resistance. $R s$ mainly due to the device itself that related with the semiconductor layer, while $R_{p}$ is based on the leakage current of the $p$ - $n$ junction [3], [4].

Generally, series part offers very little resistance, and shunt resistance being very high. According to modeling requirements, the output current could be chosen either in practical PV model (which refer to $I$, as shown in Fig. 1) or in the ideal condition $\left(I_{p v}\right.$ ideal $)$ to represent the terminal

\footnotetext{
* Corresponding author: 614575573@qq.com
} 
output of one PV module that depends on designers.

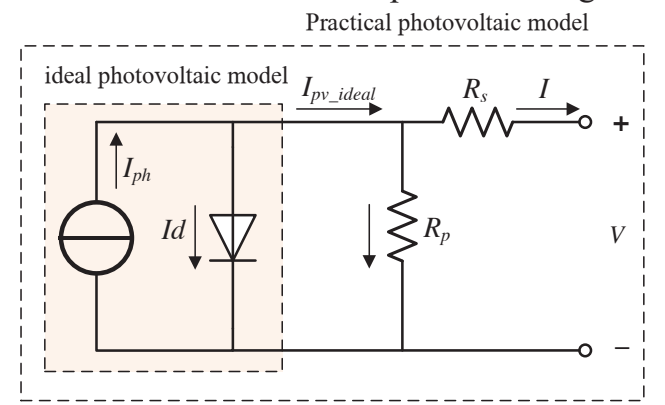

Fig. 1. A general equivalent circuit of diode PV cell model and the ideal PV mode.

The output current of a single PV module in both conditions can be written as:

$$
I=I_{p h}-I_{S}\left(e^{\left(\frac{q\left(V+I R_{s}\right)}{A k T}\right)}-1\right)-\frac{V+I R_{s}}{R_{p}}
$$

Where $I_{p h}$ is the light-generated current (or photocurrent) that describes relations between photocurrent and irradiations, temperature; $I_{\mathrm{S}}$ is the diode saturation current (or the cell saturation of dark current); $q$ is an electron charge $(1.602 \times 10-19 \mathrm{C})$; $k$ is the Boltzmann constant $(1.3807 \times 10-23 \mathrm{~J} / \mathrm{K}) ; T$ is the working temperature of cell, $A$ is an ideal factor (generally between 1 and 1.5, and mainly dependent on PV manufacture technology).

The light-generated current is mostly influenced by both solar radiations and working temperature, which is given as follows [4], [5]:

$$
I_{p h}=\frac{G}{G_{r e f}}\left(I_{p h, r e f}+C_{T}\left(T-T_{r e f}\right)\right)
$$

Where $I_{p h \text { ref }}$ is the light-generated current under standard conditions, generally refer to the external temperature at $25^{\circ} \mathrm{C}$ and irradiations is $1000 \mathrm{~W} / \mathrm{m}^{2}$. In some cases, $I_{p h, r e f}$ can be replaced by short-circuit current $I_{S C}$ under standard conditions, which can be obtained from production datasheet [5]. $G\left(\mathrm{~W} / \mathrm{m}^{2}\right)$ is the irradiation on the device surface, and $G_{r e f}$ the solar radiation at the reference condition $\left(1000 \mathrm{~W} / \mathrm{m}^{2}\right) . T$ and $T_{\text {ref }}(\mathrm{K})$ are the actual and reference temperatures respectively. $C_{T}(\mathrm{~A} / \mathrm{K})$ is the manufacturer supplied temperature coefficient.

However, sometimes when $R_{s}$ is high enough and $R_{p}$ is very low, then cell model can be considered as an ideal device, then equation (1) can be rewritten as [5]:

$$
I_{p v_{-} \text {ideal }}=I_{p h}-I_{S} e^{q V / A k T}-1
$$

\subsection{PV Array Model}

To provide greater power, a PV array consists of a set of modules that are electrically connected in series or/and parallel circuit. This is the typical configuration for a PV array model to provide the required current and voltage. If cells that connected in arrays have the same characteristic parameters. Therefore, the equivalent circuit of the PV array that corresponds with the solar cell is shown in Fig. 2.

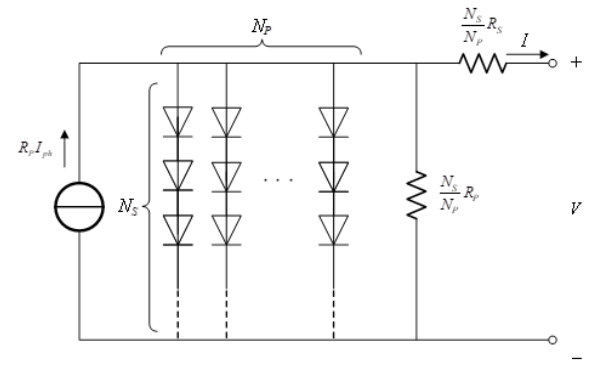

Fig. 2. Equivalent circuit for the PV module.

The equivalent circuit is shown in Fig. 2, the arrangement of cells in $N_{P}$ parallel and $N_{S}$ series respectively, the relation between voltage and current at the terminal of the circuit may be described as:

$$
I=N_{P} I_{p h}-N_{P} I_{S}\left(e^{\frac{q}{A K T}\left(\frac{V}{N_{S}}+\frac{I R_{S}}{N_{P}}\right)}-1\right)-\frac{N_{P}}{R_{P}}\left(\frac{V}{N_{S}}+\frac{I R_{S}}{N_{P}}\right)
$$

Where $E_{g}$ is material bandgap energy of the semiconductor in the PV cell $\left(E_{g}=1.12 \mathrm{eV}\right.$ for the polycrystalline silicon at $\left.25^{\circ} \mathrm{C}\right) . \quad I_{S, r e f}$ is the reverse saturation current at the reference condition, it can be approximately written as the following relation:

$$
I_{S, r e f}=\frac{I_{p h, r e f}}{e^{\left(q V_{O C} / N_{s} A k T\right)}-1}
$$

Where $V_{o c}$ is the terminal voltage in open-circuit when current equal to zero. For the single solar cell, $\mathrm{N}_{\mathrm{S}}$ $=1$.

\subsection{PV Characteristics}

After the modeling of PV cells, its characteristics can be analyzed directly. The results of the Simulink described the output power, voltage, current and relations between them. For instance, relations between output power and voltage $(\mathrm{P}-\mathrm{V})$ when irradiations $(\mathrm{G})$ set to $1000 \mathrm{~W} / \mathrm{m}^{2}$ and $500 \mathrm{~W} / \mathrm{m}^{2}$ respectively are displayed in Fig. 3, with $\mathrm{I}-\mathrm{V}$ (current and voltage relations) curves is also given.

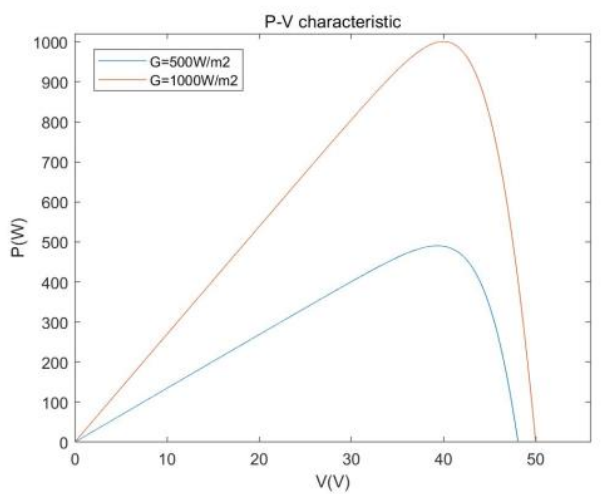

(a) P-V characteristics 


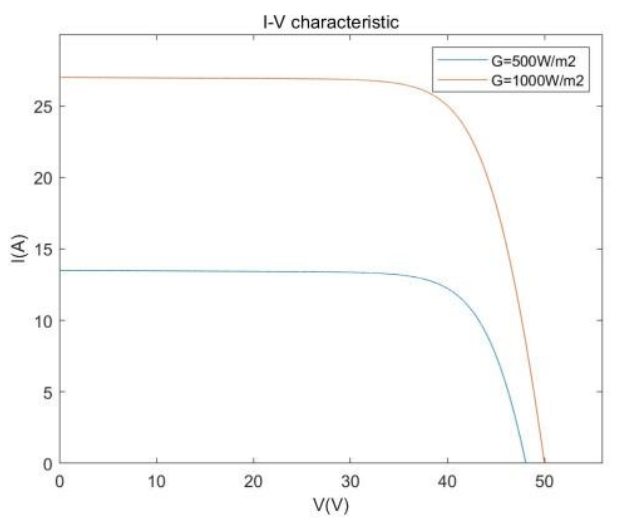

(b) V-I characteristics

Fig. 3. $P-V$ and V-I characteristics when $G=1000 \mathrm{~W} / \mathrm{m} 2$ and $500 \mathrm{~W} / \mathrm{m} 2$.

From the P-V characteristic curves showing in Fig. 3, when irradiation is $1000 \mathrm{~W} / \mathrm{m}^{2}$, the output power of the PV cells at the MPP (maximum power point) is around double the output power at MPP when $\mathrm{G}=500 \mathrm{~W} / \mathrm{m}^{2}$ (1000.6W output power at the MPP of a PV module when $\mathrm{G}=1000 \mathrm{~W} / \mathrm{m}^{2}$ and the maximum power of $489.45 \mathrm{~W}$ when $\mathrm{G}=500 \mathrm{~W} / \mathrm{m}^{2}$ ). And the voltages of MPP in both conditions are same (both $39.98 \mathrm{~V}$ at MPP). For the I-V curve shown in Fig. 3, both MPPs with different irradiations that share the same voltage, which is also $39.98 \mathrm{~V}$, where the currents of both conditions are $25.02 \mathrm{~A}$ and $12.24 \mathrm{~A}$ respectively.

\section{The Dual-loop Control for Providing Reactive power}

Normally, the PV system running under unit power factor, but it is worth mentioning that control strategy can support reactive power when a low voltage fault occurs in $\mathrm{AC}$ bus without additional compensation device. The structure of PV system with three-phase voltage source inverter is presented in 3.1, which connected with an ideal three-phase voltage source. In 3.2, the typical dualloop control for three-phase inverter I introduced. The proposed $\mathrm{Q} / \mathrm{V}$ control strategy is expounded in 3.3. Finally, simulation results are discussed.

\subsection{Three-phase Inverter Structure.}

Transformation processes of PV arrays are mainly depending on the operations of grid-connected power converters and related components. The grid-connected inverter is the key component to convert DC voltage into the required $\mathrm{AC}$ voltage for supporting utility grid or loads. As shown in Fig. 4, a single-stage topology for PV system with a typical structure of three-phase gridconnected power inverter system is displayed where the filter capacitor placed in parallel with inverter and PV array.

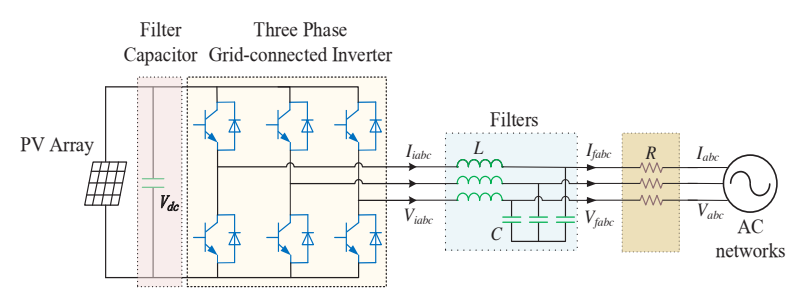

Fig. 4. Schematic diagram of the single-stage three-phase grid-connected inverter.

In this system, three-phase inverter in charge of all requirements for the appropriate three-phase AC voltage for utility grid and implementation of MPPT technology. Where $V_{d c}$ stands for the DC side voltage; $V_{i a b c}$ and $I_{i a b c}$ stand for the $a$-, $b$ - and $c$-phase output voltage and current respectively of the grid-connected inverter; $V_{f a b c}$ and $I_{f a b c}$ stand for the $a$-, $b$ - and $c$-phase voltage and current that after the filters respectively. $L=L_{a}=L_{b}=L_{c}$ that stands for the single-phase inductor value of $L C$ filter; $C$ stands for the capacitor value for very single phase when that connected in the 'star' topology. $R=R_{a}=R_{b}=R_{c}$ that stands for the line resistance value, neglecting the line inductance.

Additionally, transformations and line models are neglected when analysis. Meanwhile, suppose threephase voltage $\left(V_{a b c}\right)$ of the power grid, which represented by an AC source in the system, are balanced. The fundamental inverter equations about the voltage of the inductors and the capacitors' current are given in the following:

$$
\begin{aligned}
& L \frac{d I_{i a b c}}{d t}=V_{i a b c}-V_{f a b c} \\
& =V_{i a b c}-\left(V_{a b c}+R I_{a b c}\right) \\
& C \frac{d V_{f a b c}}{d t}=I_{i a b c}-I_{a b c}
\end{aligned}
$$

For the active and reactive power decoupling control, the coordination transformations from three phases stationary abc reference to two-phase synchronous rotating $\mathrm{dq}$ reference frame are needed. By the Park transformations, the inverter equations of state can be written as:

$$
\left\{\begin{array}{l}
u_{i d}=L \frac{d i_{d}}{d t}+R i_{d}-\omega L i_{q}+u_{d} \\
u_{i q}=L \frac{d i_{q}}{d t}+R i_{d}+\omega L i_{q}+u_{d}
\end{array}\right.
$$

Where $\mathrm{u}_{\mathrm{d}}$ and $\mathrm{u}_{\mathrm{q}}$ are respectively defined as the $\mathrm{d}$-axis and $q$-axis component grid voltage, $u_{i d}$ and $u_{i q}$ are represented as the $\mathrm{d}$-axis and q-axis component out voltage of the three-phase inverter. id and $\mathrm{i}_{\mathrm{q}}$ are defined as the d-axis and q-axis component of output current after filters that approximately equal to inverter current if capacitors can be neglected. 


\subsection{The Typical Dual-loop Decoupling Control for Three-phase PV Grid-connected Inverter}

Fig. 5 gives a typical dual-loop control topology of threephase grid-connected inverter. The entire control processes can be divided into: 1) parameters measurements from grid and transformation of coordinates processes; 2) phase locked loop (PLL) control; 3) outer-loop control or primary control; 4) inner-loop control and 5) phase width modulation (PWM) technologies.

Overall, in order to acquire certain output power by the control methods, firstly the system parameters should be measured for calculations such as active $\left(\mathrm{P}_{\text {grid }}\right)$ and reactive $\left(\mathrm{Q}_{\text {grid }}\right)$ power. And then measured powers and reference values are sent to outer-loop controller to generate reference current signals, which as reference signals for inner-loop control. The inner-loop controller aims to provide SPWW modulator with control signals, which reduces the burden on system regulator, increases system response speed and system dynamic performance.

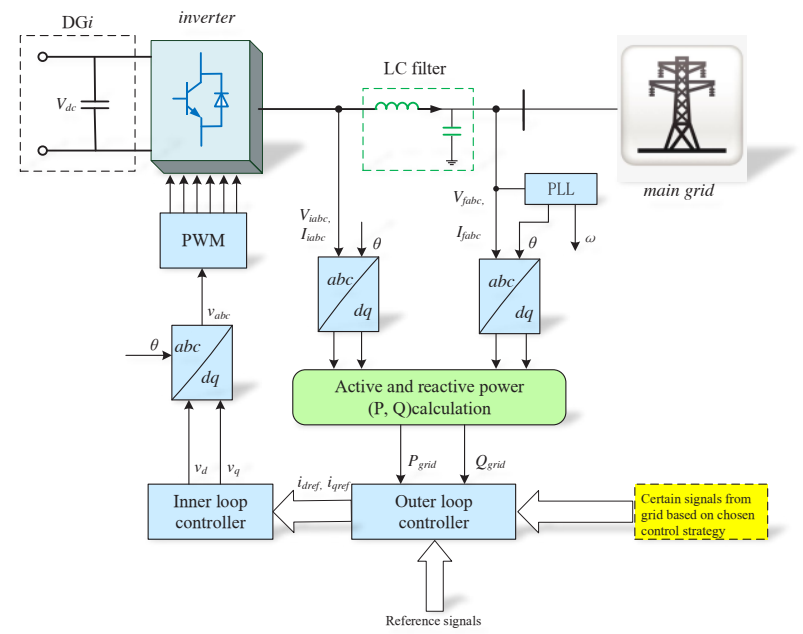

Fig. 5. A Typical Control Topology for Grid-connected Inverter.

Due to the Park transformation when a-phase is aligned with q-axis, the q-axis component of voltage equals to zero, and then power equations can be simplified, which is shown as follows:

$$
\left\{\begin{array}{l}
P_{\text {grid }}=\frac{3}{2} u_{d} i_{d} \\
Q_{\text {grid }}=-\frac{3}{2} u_{d} i_{q}
\end{array}\right.
$$

In this condition, active power only has relation with $\mathrm{u}_{\mathrm{d}}$, and reactive power only controlled by $\mathrm{u}_{\mathrm{q}}$. This is one type of the constant power control that under simplified mode.

\subsubsection{Out-loop Controller.}

For variable control purpose, different control strategies are employed in the outer-loop controller. Generally, in the PV system, trying to provide maximum output power, and working at unit power factor. Control process for active power is given in Fig.6. And $i_{q r e f}$ is set to 0 directly for the unit power factor.

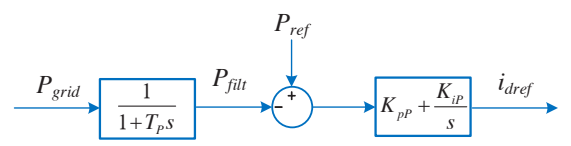

Fig. 6. Typical Outer-loop Control.

\subsubsection{Inner-loop Controller.}

From the above dq components in (8), it is difficult for designing controller due to the coupling of the d-axis and q-axis. The strategy of feed-forward decoupling control can be employed and introduce PI regulator to realize stable operation in the close-loop. The control relations are given in follows [6]:

$$
\left\{\begin{array}{l}
u_{i d}=\left(K_{P}+\frac{K_{I}}{s}\right)\left(i_{\text {dref }}-i_{d}\right)-\omega L i_{q}+u_{d} \\
u_{i q}=\left(K_{P}+\frac{K_{I}}{s}\right)\left(i_{\text {qref }}-i_{q}\right)+\omega L i_{q}+u_{d}
\end{array}\right.
$$

The feed-forward decoupling control and coupling compensation can realize independent control of $\mathrm{dq}$ components. The diagram of the inner-loop current controller is shown in Fig.7.

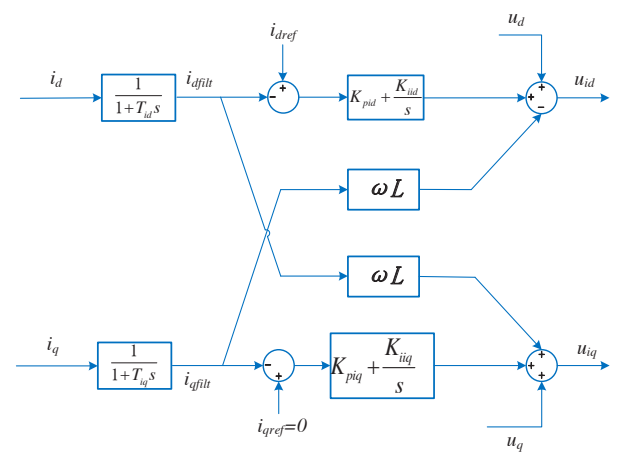

Fig. 7. Typical Inner-loop Control.

\subsection{Reactive power/Voltage Control in PV System.}

Sometimes PV arrays are required to provided certain reactive power for voltage fluctuation or faults, and improve low-voltage ride through capability (LVRT) [7]. A reactive control topology is employed to provide certain output reactive power. Due to the P-V parameters that displayed in Fig.3, a strategy by means of controlling output PV array voltage $\left(\mathrm{V}_{\mathrm{dc}}\right.$, shown in Fig. 5) to regulate output power $(\mathrm{P})$ is introduced. The maximum power point tracking (MPPT) algorithm is used to find operation voltage $V_{\text {mpp }}$ for $P V$ arrays that corresponds with the maximum output power. And then control $V_{\text {mpp }}$ as the reference signal, which can be shown in Fig.8, to regulate $\mathrm{V}_{\mathrm{dc}}$ as well as $\mathrm{P}$ [8]. The generated signal $\mathrm{i}_{\mathrm{dref}}$ is also sent 
to inner-loop controller to regulate P. Reactive power (Q) can also be controlled by PI controller where the $\mathrm{i}_{\mathrm{qref}}$ is sent to inner-loop controller. While the inner control is as same as the typical dual-loop control method.

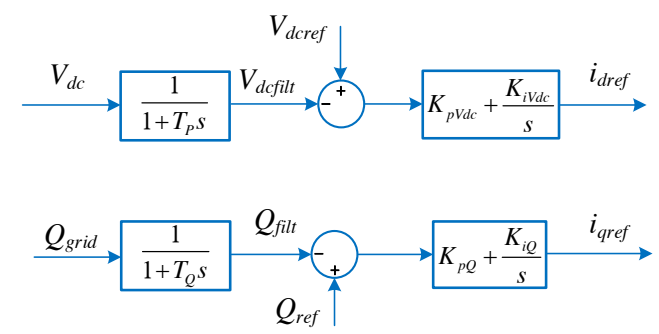

Fig. 8. Typical Q/V Control.

\section{Simulation Results}

For the simulation model of the system, the resistance for per phase in the balanced lines is $0.0001 \Omega$, inductance value is $125 \mu \mathrm{H}$, The rms (root mean square) value of phase to phase voltage for the main grid is $230 \mathrm{~V}$.

In case 1, for the nominal condition of PV arrays, setting $\mathrm{i}_{\text {qref }}=0$, which means running at unit power factor. While in case2, based on the decoupling control and $\mathrm{Q} / \mathrm{V}$ control strategy, active power is still required, additional reactive power is expected. According to (9), setting $\mathrm{Q}_{\mathrm{ref}}=28.8 \mathrm{kVar}$. The active power of PV arrays still output the maximum values under its external conditions. Besides, in order to test the dynamic working conditions of the PV system, in the both cases, solar irradiation changed from $1000 \mathrm{~W} / \mathrm{m}^{2}$ to $500 \mathrm{~W} / \mathrm{m}^{2}$ at 1 second.

According to the simulation structure, the output active power and reactive power in grid side under both control topology are measured for testing, which are given in Fig. 9.

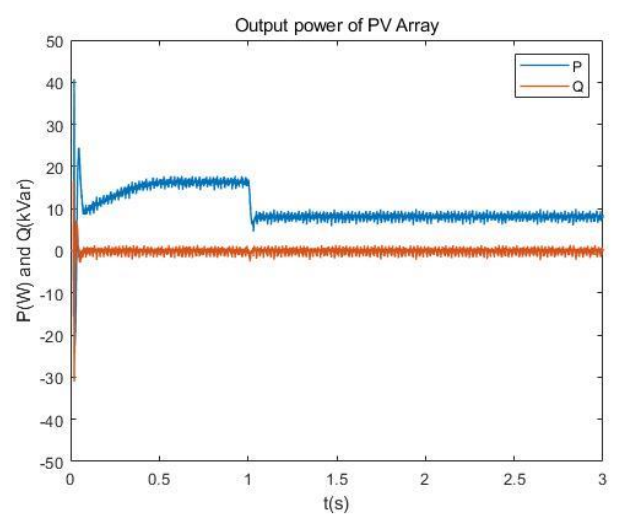

(a) Case 1: the typical dual-loop control.

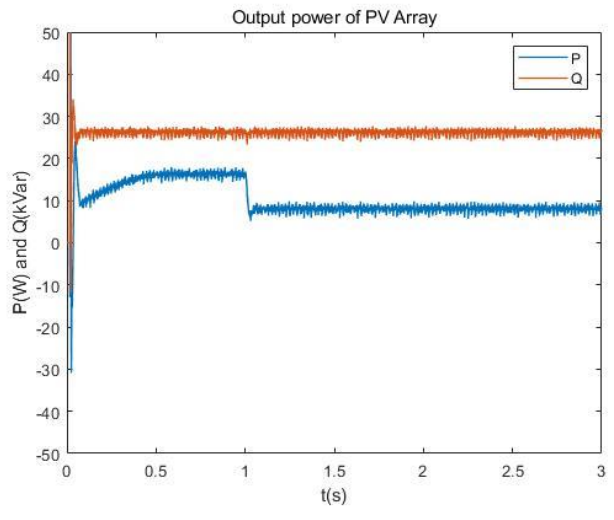

(b) Case 2: the $\mathrm{Q} / \mathrm{V}$ control strategy.

Fig. 9. Curves of $P$ and $Q$ in different control conditions.

- In both cases, at 1 second, the output power deduces half from $17.97 \mathrm{~kW}$ to $8.95 \mathrm{~kW}$ when irradiation changed from $1000 \mathrm{~W} / \mathrm{m}^{2}$ to $500 \mathrm{~W} / \mathrm{m}^{2}$, which shows quite perfect dynamic performance of active power control of PV arrays.

- In case 1 , when setting $\mathrm{i}_{\mathrm{qref}}=0$, it can directly control output zero reactive power, which realizes working in unity power factor.

- Compared with simulation results in case1 and case2, since the reactive power control, blue lines (reactive power) changed, but red lines (active power) still maintained maximum output power under the control order. Thus, it verified the effectiveness and accuracy of decoupling control.

- In case2, it is shown that the reactive power supporting in Fig. 9(b), the $\mathrm{i}_{\mathrm{qref}}=-1.2$, according to (9), and the base value of $\mathrm{Q}$ is $16 \mathrm{kVar}$, as a result, the calculated value of $\mathrm{Q}$ in grid side is given.

$$
Q_{\text {grid }}=-\frac{3}{2} u_{d} i_{q}=-\frac{3}{2} \times 1 \times(-1.2) \times 16=28.8 \mathrm{kVar}
$$

- The curves of active power (P, red line) in case 1 and case 2 are almost same, which verified the strategy is feasible that regulate $\mathrm{P}$ by means of controlling $\mathrm{V}$.

\section{Conclusions}

The simulation results show that the output active power is quite perfect even in case of irradiation changes. On the other hands, reactive power is required in many conditions and for the enhancements of low-voltage ride through capability. The proposed reactive power control method that based on the decoupling dual-loop control strategy can provide certain reactive power effectively. Simulation results verify the effectiveness and accuracy of the $\mathrm{Q} / \mathrm{V}$ control.

Project Supported by National Natural Science Foundation of China (NSFC) (51761145106). 


\section{References}

1. Z. Gao, S. Li, X. Zhou, and Y. Ma. An overview of $\mathrm{PV}$ system, IEEE International Conference on Mechatronics and Automation, 587-592 (2016)

2. J. Rocabert, A. Luna, F. Blaabjerg, and P. Rodríguez. Control of Power Converters in AC Microgrids. IEEE Trans. Power Electron, 27, 4734-4749 (2012)

3. M. G. Villalva, J. R. Gazoli, and E. R. Filho. Comprehensive Approach to Modeling and Simulation of Photovoltaic Arrays. IEEE Trans. Power Electron, 24, 1198-1208 (2009)

4. Y. Jiang, J. A. A. Qahouq, and I. Batarseh. Improved solar PV cell Matlab simulation model and comparison. In: Proc. of 2010 IEEE International Symposium on Circuits and Systems, 2010, pp. 27702773.
5. H.-L. Tsai, C.-S. Tu, and Y.-J. Su, Development of Generalized Photovoltaic Model Using MATLAB/SIMULINK', 6 (2008)

6. T. Huang, X. Shi, Y. Sun, and D. Wang. Three-phase photovoltaic grid-connected inverter based on feedforward decoupling control. 2013 International Conference on Materials for Renewable Energy and Environment, 2, 476-480 (2013)

7. A. V. Timbus, R. Teodorescu, F. Blaabjerg, M. Liserre, and P. Rodriguez. Linear and Nonlinear Control of Distributed Power Generation Systems. 2006 IEEE Industry Applications Conference FortyFirst IAS Annual Meeting, 2, 1015-1023 (2006).

8. T. Huang, X. Shi, Y. Sun, and D. Wang. Three-phase photovoltaic grid-connected inverter based on feedforward decoupling control. International Conference on Materials for Renewable Energy and Environment, 2, 476-480. (2013) 